while they were on a gluten-free diet, but we believe that even these can be explained on the natural history of the disease. After all, the average duration of dermatitis herpetiformis without a gluten-free diet is four years, and we have patients who have had spontaneous remissions (without a glutenfree diet) for periods of up to four years. More cases who needed no dapsone while on their diet and relapsed when the diet was stopped, like case 17 in the series of Drs. Marks and Whittle, are needed to establish that gluten has an effect on the rash, and such case histories have not yet been published. We believe indeed that none of the published evidence shows that the rash, in contrast to the enteropathy, of dermatitis herpetiformis is improved by gluten withdrawal.-We are, etc.,

\section{JANET MARKS.} SAM SHUSTER.

\section{Department of Dermatology,} Royal Victoria Infirmary,
Newcastle upon 'Tyne.

\section{REFERENCES}

Shuster, S., Watson, A. J., and Marks, J., Lancet, 1968, 1, 1101 .

Marks, J., and Shuster, S., British Medical fournal, 195s, 4 , 455 . 1970 . In press.

Thuster, $S$ and Marks, J Systemic Effects Skin Disease p. 117. London. Heinemann Medical books. In press.

ry, L., McMinn, R. M. H., Cowan, J. D., and
Hoffbrand, A. V., Archives of Dermatalogy, $1969,100,129$

'Smith, E. L., Transactions of St. Fohn's Hospital Dermatalogical Society, 1966 52, 176.

\section{Marrow Suppression from Mercury Poisoning?}

SIR,-Workers exposed to mercury in industry are found to excrete increased amounts of mercury in their urine. The World Health Organization figures suggest that more than $300 \mu \mathrm{g}$. $/ 1$. of urine should be taken as an index of over-exposure. Nevertheless, figures well over this level, even amounting to several milligrams of mercury per litre of urine, may be found in many mercury workers without any clinically ap parent ill effects. ${ }^{1}$ The diagnosis of mercury poisoning as opposed to simple overexposure has traditionally been taken to depend on finding such symptoms as stomatitis, erethism, and tremor. There are but few references in the literature on the effects of chronic mercury exposure on the haemopoietic system. Thrombocytopenia has been described in man, ${ }^{2}$ and Kossman et al. have reported a reduction in the platelet counts of rabbits experimentally exposed to mercury vapour. Wilson ${ }^{4}$ reported death from aplastic anaemia in a patient taking Hydrarg. cum creta tablets for 33 years, whose urine contained $674 \mu \mathrm{g}$. of mercury in 24 hours, but in whom there were none of the classical symptoms of mercury poisoning. The following report is of a mercury worker who died of aplastic anaemia, with a high level of mercury in the urine.

A 59-year-old male developed a purpuric rash after working for 6 months as a mercury filler in a factory making thermometers. When first seen his blood count showed a haemoglobin of $11.8 \mathrm{~g} . / 100 \mathrm{ml}$., white cells 900 per cu. $\mathrm{mm}$., neutrophils $20 \%$ (180 per cu. mm.), platelets less than 10,000 per cu. $\mathrm{mm}$. Iliac crest bone marrow showed acellular fragments, severely suppressed granulopoiesis, and absent megakaryocytes. The urine contained $1,010 \mu \mathrm{g}$. of mercury per litre. Intractable diarrhoea and a rapidly falling haemoglobin level necessitated admission to hospital, where he was transfused and treated with high dosages of steroids. Later, 2, 3-dimercaptopropanol (BAL) $\quad(800 \quad \mathrm{mg}$ daily) was given. He died with signs suggesting cerebral haemorrhage 20 days after his first at tendance. None of the traditional signs of mercury poisoning were detectable. Careful inquiry indicated that he had had no contact with any other drugs or chemicals likely to injure the marrow. Post-mortem examination (Dr. R. E Cotton) confirmed the marrow aplasia and showed, in addition, haemorrhagic "colitis" and multiple small haemorrhages in the brain, endocardium, and renal calices.

In most cases of aplastic anaemia, the question of whether a particular substance is responsible is answered by an assumption based upon previously documented relationships. Similarly, in this case no dogmatic conclusion can be drawn, but the findings are reported to draw attention to the possibility that some degree of marrow suppression might occur with high body concentration of mercury.

We are indebted to Dr. M. H. P. Sayers, of the Medical Branch of the Department of Employ ment and Productivity, for the urinary mercury estimations.-We are, etc.

D. R. RYRIE.

P. J. TOGHILL

M. K. Tanna.

G. N. Galan.

Department of Clinical Haematology, City Hospital,

REFERENCES

1 Brown, J. R., Kulkarni, M. V., Medical Services
尹ournal, CCanada, 1967, 23, 786.
2 Butt, E. M., Simonsen, D. G., American fournal
of Clinical Pathology, 1950, 20, 716.
3 Kossmann, S., Kosmider, S., Dabrowski, Z., Acta
Medica Polona, 1968, 9, 95.
4 Wilson, D. R., British Medical fournal, 1966, 2,
1534.

\section{Voluntary Sterilization}

SIR,-In his helpful letter (13 December 1969) Dr. P. H. Addison, secretary of the Medical Defence Union, stresses the principle that vasoligation may not be carried out under the National Health Service unless there is a medical indication for the operation. There is, he says, no distinction between men and women. In either case the operation must be necessary to protect the physical or mental health of the patient.

Two questions arise here: What, in this context, is meant by the terms physical and mental health; and to what extent do women differ from men in their eligibility for sterilization under the N.H.S. on grounds of physical and mental health respectively? There is little doubt as to what is meant by physical health. On this ground tubal ligations, mostly connected with foreseen complications and aftermaths of future pregnancies, are widely performed under the N.H.S. But manifestly there are no equivalent grounus for performing vasectomies. Mental health, however, is less easy to define. The World Health Organization has described it in the following terms: "Health is a state of complete physical, mental and social well-being and not merely the absence of disease or infirmity."

This statement, which has been understandably criticized, is quoted here because, in spite of its over-comprehensiveness, it gives substance to the view that a person's mental health can fall short of what it ought to be without that person being overtly ill In respect of mental health, however defined, the two sexes are here more on a par than in respect of physical health. If a couple has lost confidence in contraception because, despite precautions, one or more unwanted pregnancies have occurred, misgivings and anxieties will be focused by both on the coital act. The more numerous the failures the greater and more natural the anxiety of the couple.

Dr. Addison mentions the Simon Population Trust. A noteworthy finding of a recently completed follow-up, organized by the Trust, of over 1,000 vasectomized subjects (a report of the follow-up is now being prepared) was that the commonest reason prompting men to seek vasectomy was their dislike of contraception though most gave several reasons. Nearly $80 \%$ of the respondents to a questionary gave this answer. The next most common reason was the husband's wish to spare his wife the more serious operation of tubal ligation. Coitus in terruptus remains one of the most commonly practised and least reliable methods of birth control. In my experience coitus interruptus is harmless to most couples, but not to all. More readily than other methods it generates stresscausing anxieties about the possibilities of failure. In the above-mentioned follow-up questions were asked about the effects of vasectomy on the general health and on the sexual lives of both the respondents and their wives. In respect of their sexual ives more than threequarters of both sexes reported improvements. Men do not apply for vasectomy for frivolous reasons. They apply because they think that they and their wives would be happier and their marriages more harmonious after it than without it: because, in short, it would conduce to their mental health.

It is desirable that a man wishing to be vasectomized should consult his family doctor. If the latter is of the opinion that vasectomy would spare the applicant and his wife coital anxieties and other worries, and accordingly recommends it, then, I suggest, a surgeon would be justified on grounds of mental health in performing the operation under the N.H.S.-I am, etc.,

Shamley Green,
Surrey.

\section{P. BLACKER.}

\section{Epidemic Malaise}

SIR,-I am glad that Drs. C. P. McEvedy and A. W. Beard have had the grace to say that their opinions (3 January, p. 7), on the Royal Free Hospital epidemic of 1955 are their own, as their paper is an example of the errors that one is apt to make in retrospective assessments of case notes made by people one doesn't know well. It also betrays considerable lack of historical awareness of the situation obtaining at the Royal Free Hospital at that time and of the full history of the epidemic. This includes the physical separation of the preclinical medical school from the hospital, which itself was split into six main divisions with the result that clinical students were pretty scattered for much of the course. Nobody who really knew the physicians who looked after most of the cases would ever suggest that they would overlook hysteria in the differential diagnosis of an obscure and bizarre illness, and indeed the tendency would 